\title{
A genetic marker at the glucokinase gene locus for Type 2 (non-insulin-dependent) diabetes mellitus in Mauritian Creoles
}

\author{
K.C.Chiu ${ }^{1}$, M.A.Province ${ }^{2}$, G.K.Dowse ${ }^{3}$, P.Z.Zimmet ${ }^{3}$, G. Wagner ${ }^{4}$, S. Serjeantson ${ }^{4}$ and M. A.Permutt $^{1}$ \\ ${ }^{1}$ Metabolism Division, Department of Internal Medicine and ${ }^{2}$ Division of Biostatistics, Washington University School of Medicine, \\ St.Louis, Missouri, USA, ${ }^{3}$ International Diabetes Institute, Caulfield General Medical Center, Caulfield South, Victoria, and \\ ${ }^{4}$ Department of Human Biology, the John Curtin School of Medical Research, Canberra, Australia
}

Summary. The prevalence of Type 2 (non-insulin-dependent) diabetes mellitus is high in Mauritius, a multiethnic island nation in the southwestern Indian Ocean. Evaluation of candidate genes in the different ethnic groups represents a means of assessing the genetic component. As glucokinase is known to be a key regulator of glucose homeostasis in liver and pancreatic Beta-cells, the human gene was isolated and a dinucleotide repeat $(\mathrm{CA})_{n}$ marker was identified at this locus. A polymerase chain reaction assay was developed, and alleles differing in size were observed in individuals, according to the number of repeats in the amplified fragment. Eightyfive Creoles and 63 Indians of known glucose tolerance status were typed by amplification of genomic DNA for this dinucleotide $(\mathrm{CA})_{\mathrm{n}}$ repeat marker. Four different alleles were observed including $Z$, the most common allele, and $Z+2, Z+4$, and $Z+10$, which differed from $Z$ by 2,4 , and 10 nucleotides respectively. In Mauritian Creoles, the frequency of the $\mathrm{Z}+2$ allele was greater in Type 2 diabetic subjects than in control subjects ( $23.8 \%$ vs $8.9 \%, p=0.008)$, and the frequency of the $Z$ allele was lower in Type 2 diabetic sub- jects $(60 \%$ vs $75.6 \%, p=0.03)$. Analysis with univariate logistic regression models indicated that the $\mathrm{Z}+2$ allele had the highest odds ratio, 3.08 (95\% confidence interval 1.14 $8.35, p=0.0416$ ), among the other risk factors (age, sex, body mass index, and waist/hip ratio). The multivariate odds ratio for Type 2 diabetes was 2.88 ( $95 \%$ confidence interval 0.98 $8.50, p=0.0551)$. In contrast, in the Mauritian Indian population, no differences were noted between the frequency of any glucokinase allele in the Type 2 diabetic and control groups. These data suggest that the $\mathrm{Z}+2$ allele is an important risk factor for Type 2 diabetes in Mauritian Creoles, but not in Mauritian Indians, and also imply that the glucokinase gene may play a role in the pathogenesis of Type 2 diabetes in Mauritian Creoles. Further studies are needed to define the nature of this defect.

Key words: Type 2 (non-insulin-dependent) diabetes mellitus, glucokinase, population association study, polymorphism, dinucleotide $(\mathrm{CA})_{\mathrm{n}}$ repeat, obesity, genetic.
Mauritius is an island nation in the southwestern Indian Ocean east of Madagascar. It is populated by Creole (mixed African, Malagasy, European, and Indian origin), Indian and Chinese ethnic groups. Mortality rates from diabetes on this island have been noted to be one of the world's highest [1]. A marked change in the mortality profile took place after World War II, with a rising standard of living associated with industrialization. A recent epidemiologic study in Mauritius revealed that the prevalence of Type 2 (non-insulin-dependent) diabetes mellitus in adults, at about $12 \%$, was remarkably similar across ethnic groups $[1,2]$. African Blacks and Indians are known to have a low prevalence of Type 2 diabetes mellitus when living a traditional rural lifestyle $[1,3,4]$, but the prevalence increases dramatically after migration and modernization $[5,6]$. A previous study concluded that potent environmental factors including body mass index, ab- dominally distributed fat, and physical inactivity are the major independent risk factors for Type 2 diabetes in Mauritians [2].

Familial aggregation of Type 2 diabetes in African Blacks and Indians suggests that genetic factors might also play a role in the pathogenesis of the disease [3,7]. In other racial groups, the genetic predisposition to Type 2 diabetes has been suggested by population $[8,9]$, family and twin studies [10]. Type 2 diabetes in man is not easily explained by simple Mendelian models, however, as the multifactorial nature of the disease confounds genetic studies. One way of identifying the polygenes that contribute susceptibility to Type 2 diabetes mellitus would be identification of a genetic marker at a particular locus through population studies [11], suggesting that variation at this locus may increase or reduce the risk of developing Type 2 diabetes. Several likely candidate genes have been 
A

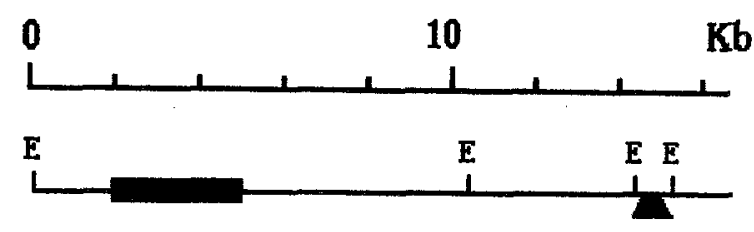

B

5'-TTGGTCAGTGTAGGCTGAACTCATGTCCTGGGTCTGTGCCCA

TCTGTTTCTCTCTATCCTTCTGTCTCTCTCTTTTGTCTCTC

TCTCTCTCTCACACACACACACACACAAACACAC

ACACCACATACACACACCATATACATTCTACCCTCAGTT

TATTCCAAACAACACTAATACAGGCAGTHTTGGTGTGGG-3'

C

$\begin{array}{ll}Z & \left.:[\mathrm{CT}]_{4} \text { TTTGT }_{\mathrm{TCT}}\right]_{7}[\mathrm{CA}]_{9} \text { AA }[\mathrm{CA}]_{4} \text { CCACATA }[\mathrm{CA}]_{3} \\ \mathrm{Z}+2 & :[\mathrm{CT}]_{4} \text { TTTGT }[\mathrm{CT}]_{6}[\mathrm{CA}]_{11} \text { AA }[\mathrm{CA}]_{4} \text { CCACATA }[\mathrm{CA}]_{3} \\ \mathrm{Z}+4 & :[\mathrm{CT}]_{4} \text { TTTGT }[\mathrm{CT}]_{6}[\mathrm{CA}]_{12} \text { AA }[\mathrm{CA}]_{4} \text { CCACATA }[\mathrm{CA}]_{3} \\ \mathrm{Z}+10:[\mathrm{CT}]_{4} \text { TTTGT }[\mathrm{CT}]_{6}[\mathrm{CA}]_{15} \text { AA }[\mathrm{CA}]_{4} \text { CCACATA }[\mathrm{CA}]_{3}\end{array}$

Fig. 1A-C. Restriction map and DNA sequence of the compound imperfect dinucleotide (CA) $)_{\mathbf{n}}$ region at the glucokinase locus on chromosome 7p. A EcoRI (E) restriction map of a lambda clone containing human genomic DNA. The solid box indicates the region containing glucokinase exons, and the inverted triangle refers to the amplified region containing the dinucleotide $(\mathrm{CA})_{n}$ repeat element. B The DNA sequence of the $(C A)_{n}$ repeat region in the most common sized or Z allele. Underlined sequences are the synthetic oligonucleotide primers ( \#9509 primer is at $5^{\prime}$-end and \# 9510 primer is at $3^{\prime}$-end with complimentary sequence) used for polymerase chain reaction (PCR) amplification. C The DNA sequences of the dinucleotide repeat regions, determined by direct genomic sequencing, from representative $Z, Z+2, Z+4$, and $Z+10$ alleles

evaluated without definite conclusions [10], suggesting that these loci are not major contributors to the disease.

The enzyme glucokinase [E.C.2.7.1.1.] regulates blood glucose levels by controlling hepatic glucose utilization and glycogen storage, and by acting as a glucose sensor which regulates insulin production in pancreatic islet Beta-cells $[12,13]$. The gene for this key glucose metabolic regulator has not been evaluated in Type 2 diabetes mellitus. Cloning the human glucokinase gene [14], and identifying a polymorphic dinucleotide $(\mathrm{CA})_{\mathrm{n}}$ repeat marker at the glucokinase locus on chromosome $7 \mathrm{p}$ [15], provided the opportunity to develop a polymerase chain reaction (PCR) assay for various sized alleles, and to conduct a study in the Mauritian Creole and Indian Type 2 diabetes mellitus patients and control subjects.

\section{Subjects and methods}

\section{Background}

According to most recent estimates, $70 \%$ of the Mauritian population are Indian, $2.1 \%$ are Chinese, and nearly all of the remaining $27.9 \%$ are Creoles. The Creoles are of African and Malagasy an- cestry, with various amounts of European and, to a lesser extent, Indian genetic admixture. The details of the study protocol may be found in earlier reports $[1,2]$. Briefly, the epidemiological study was conducted in Mauritius in April 1987, on a random cluster sample of over 5,000 subjects aged 25-74 years. The classification of diabetes mellitus was modified from the WHO criteria [16]. Diabetes was defined if subjects reported a history of diabetes and were currently taking either an oral agent or insulin, or if not on medication, if they had a fasting plasma glucose $\geq 7.8 \mathrm{mmol} / \mathrm{l}$, or a 2 -h plasma glucose $\geq 11.1 \mathrm{mmol} / \mathrm{l}$. Diabetes was also defined in those subjects without a previous history of diabetes but in whom the 2 -h plasma glucose was $>11.1 \mathrm{mmol} / 1$.

\section{Study sample and DNA preparation}

A sub-sample of subjects from the main survey population was selected for genetic studies, which included serological HLA typing, plus storage of plasma and buffy coats, in the following manner. For the main survey, two teams worked at different parts of the island, and each team surveyed between 100-150 subjects per day. At each survey site, on most but not all survey days, up to 12 subjects were entered into the genetic sub-study. These were the first six unrelated subjects giving a positive personal history for diabetes, and the first six unrelated subjects aged over 50 years who had no personal history of diabetes. At the time of fasting blood collection, these subjects had an additional $15 \mathrm{ml}$ heparinized specimen collected which was used for harvesting buffy coats used for the present study. In a few instances the elderly "control" subjects were found during the oral glucose tolerance test to actually have diabetes and hence they became "cases". The control group for the present study were all non-diabetic at the time of testing, but some individuals did have impaired glucose tolerance. As the sample size was limited, to maximize data for analysis these individuals were included. If some of these individuals are really "pre-diabetic subjects", this would only serve to reduce differences at the glucokinase locus. Thus, in this respect any differences observed could be considered minimal.

Because it was felt that Creoles were the most interesting group for genetic studies, they were over-sampled relative to Indians. Larger sample size was desirable. However, the present study was limited by the number of DNA samples which were collected in April 1987. Ultimately genomic DNA for the present study was available on 85 Creoles ( 40 diabetic patients and 45 control subjects) and 63 Indians (31 diabetic patients and 32 control subjects). Among the Indians, $87 \%$ (55/63) of the Indians were Hindu, and the remaining $13 \%$ were Muslim. Genomic DNA was prepared from peripheral blood lymphocytes by routine phenol/chloroform extraction.

\section{PCR assay for polymorphic dinucleotide repeat}

Genomic DNA was amplified with a pair of PCR primers (Fig. 1B) in $10 \mu \mathrm{l}$ volumes containing $100-250 \mathrm{ng}$ EcoRI digested or uncut genomic DNA, 4 pmol unlabelled primer \#9509 3.6 pmol unlabelled primer \# 9510,0.4 pmol primer \#9510 which was end-labelled with [ $\left.{ }^{32} \mathrm{P}\right] \mathrm{ATP}$ by $\mathrm{T}_{4}$ polynucleotide kinase $200 \mu \mathrm{mol} / \mathrm{l}$ each $\mathrm{dNTP}, 1.5 \mathrm{mmol} / 1 \mathrm{MgCl}_{2}$, and 0.25 units Amplitaq polymerase in the buffer supplied in Gene AMP kit (Perkin Elmer-Cetus, Norwalk, Conn., USA). Samples were processed through initial denaturation for $3 \mathrm{~min}$ at $94^{\circ} \mathrm{C}, 25$ to 30 cycles of amplification which consisted of $1 \mathrm{~min}$ at $94^{\circ} \mathrm{C}$ (denaturation) and $1 \mathrm{~min}$ at $66^{\circ} \mathrm{C}$ (annealing-extension), and final elongation at $66^{\circ} \mathrm{C}$ for $9 \mathrm{~min}$ in a Perkin Elmer-Cetus thermal cycler. After being denatured at $90^{\circ} \mathrm{C}$ for $2 \mathrm{~min}$ in $50 \%$ formamide- $10 \mathrm{mmol} / \mathrm{l}$ EDTA solution, aliquots ( 2 to $4 \mu \mathrm{l})$ of amplified samples were electrophoresed on a DNA sequencing gel containing $6 \%$ acrylamide, $7 \mathrm{mmol} / 1$ urea, and $1 \mathrm{x}$ Tris-borate EDTA buffer (TBE) for $2.5 \mathrm{~h}$ at 75 watts in $0.6 \mathrm{x}$ TBE buffer. Gels were then fixed, dried, and processed for autoradiography as described pre- 


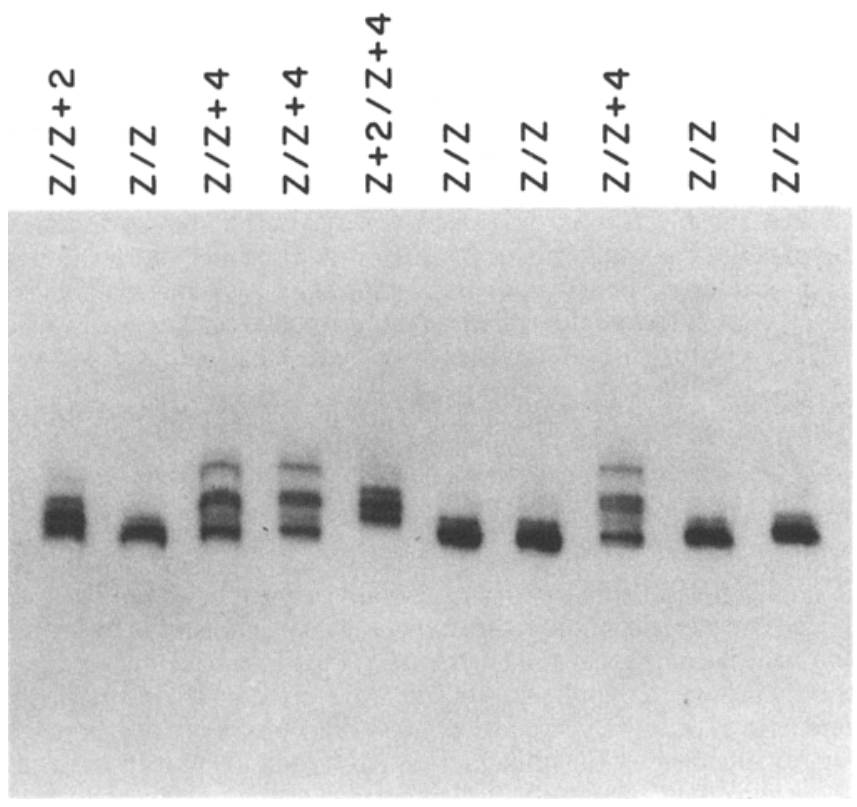

Fig. 2. Representative autoradiogram of polymerase chain reaction $(P C R)$ amplified DNA containing the dinucleotide $(C A)_{n}$ region at the glucokinase locus from ten unrelated individuals. See Figure $1 \mathrm{C}$ for the sequence of each allele. $Z / Z$ refers to an individual homozygous for the $Z$ allele, $Z / Z+2$ refers to an individual heterzygous, with one $Z$ allele and one $Z+2$ allele, etc

viously [15] as well as sequencing of dinucleotide region in the representative alleles from genomic DNA. When necessary, DNA was analysed repeatedly and/or sequenced so that each allele could be assigned unambiguously.

\section{HLA-typing}

Polymerase chain reaction (PCR) products amplified with exon 2 HLA-DRB primers [17] were screened with $16\left[{ }^{32} \mathrm{P}\right]$-labelled 19 mer probes for HLA-DR typing. The PCR amplification conditions and sequence-specific oligonucleotide (SSO) hybridization procedures were as described previously [18]. For HLA-DQ typing, PCR primers and SSOs for DQA1 (11 probes) and DQB1 (14 probes) have been given elsewhere [18]. Oligonucleotides were synthesized locally (Australia) on an Applied Biosystems Inc. (ABI, Foster City, Calif., USA) Model 380B nucleic acid synthesizer. HLA-DR, DQ types were determined in Creoles, for 37 Type 2 diabetic patients and for 50 control subjects with normal or impaired glucose tolerance. Alleles were not assigned in some instances where a novel combination of HLA-DR and -DQ SSO patterns were observed.

\section{Data analysis}

Genotypic frequencies were calculated for each group and were tested for Hardy-Weinberg equilibrium. Allelic frequencies were derived from the number of the genotypes. Differences between groups in quantitative variables were evaluated by unpaired (twotailed) $t$-tests and differences in proportions werc evaluated by Chisquare test. The association of polymorphic alleles with Type 2 diabetes were analysed by $2 \times 2$ contingency tables. A Chi-square test of independence was performed with Yates' correction applied where indicated. Univariate odds ratios were computed to assess the magnitudes of effects. In order to assess the effect of obesity, the data were further divided into two subgroups according to body mass index ( $\leq$ or $>24.267$ for men, and $\leq$ or $>25.768$ for women) or waist/hip ratio ( $\leq$ or $>0.913$ for men, and $\leq$ or $>0.838$ for women), as defined previously [2]. These levels defined the upper tertile [2] of the distribution in the total survey population for each sex.

We utilized a stepwise approach and fit a series of categorical models, using a logistic response function [19] to assess the risk of Type 2 diabetes, analysed by SAS/STAT (SAS Institute Inc., Cary, NC, USA). Due to the relatively large number of genotypes and relatively low frequencies of some genotypes, we looked for the allele(s) which had the largest detectable effect on the risk, assuming that the majority of the alleles (null) had little or no effect for the risk of Type 2 diabetes. In a stepwise fashion, we added the most significant allele while considering all those yet selected as null, until the addition of alleles no longer increased the significance of the model. Multivariate analysis was performed with consideration of the effects of other covariates (sex, age, body mass index, and waist/hip ratio) on the risk, to estimate the independent association between Type 2 diabetes and the genotype of interest. Adjusted odds ratios of the relative risk of Type 2 diabetes associated with each risk factor (binary in genotype and sex, per year in age, per $\mathrm{kg} / \mathrm{m}^{2}$ in body mass index, and per 0.1 increase in waist/hip ratio) were estimated.

\section{Results}

\section{Polymorphic dinucleotide $(C A)_{\mathrm{n}}$ repeat}

A dinucleotide $(\mathrm{CA})_{\mathrm{n}}$ repeat element was found approximately 10 kilobase $3^{\prime}$ of the human glucokinase gene [15], as shown in Figure $1 \mathrm{~A}$. From the sequence, a pair of oligonucleotide primers (Fig.1B) were chosen which flanked the repeated region in a 195 base pair fragment. After PCR amplification of genomic DNA, four different sized alleles were found in the Creoles, and three alleles in Indians. As shown in Figure 2, one major band was seen in homozygous subjects, and two major bands in heterozygous subjects. The additional minor bands, generated during the amplification reaction, were not a reflection of somatic mosaicism [20,21]. Using an M13 sequencing ladder, single nucleotide (nt) differences in alleles could be detected. Repeated analysis showed that for any individual DNA the pattern was consistent, and genotypes could be unambiguously assigned.

By direct genomic sequencing of the repeat regions, it was determined that the most common allele, defined as $\mathrm{Z}$ with 195 base pairs, was composed of five repeat elements interrupted by three non-repeat elements (Fig. 1B). The differences in the sizes of alleles was derived from the variations in the number of repeats at two immediately adjacent $C T$ and $C A$ repeats (Fig. $1 C$ ). Thus, the $Z+2$ allele differed from the $Z$ allele by a net of $2 \mathrm{nt}$, the $Z+4$ allele by a net of $4 \mathrm{nt}$, etc. According to the classification of Weber [22], this was a compound imperfect dinucleotide repeat.

\section{Clinical characteristics of the study population}

The mean age of the diabetic and control groups was similar within both Creoles and Indians (Table 1). There appeared to be a preponderance of females among the Creole diabetic patients (not significant), and of males in the Indian diabetic patients (not significant), reflecting the differences in prevalence between the sexes observed in 
Table 1. Characteristics of the study population

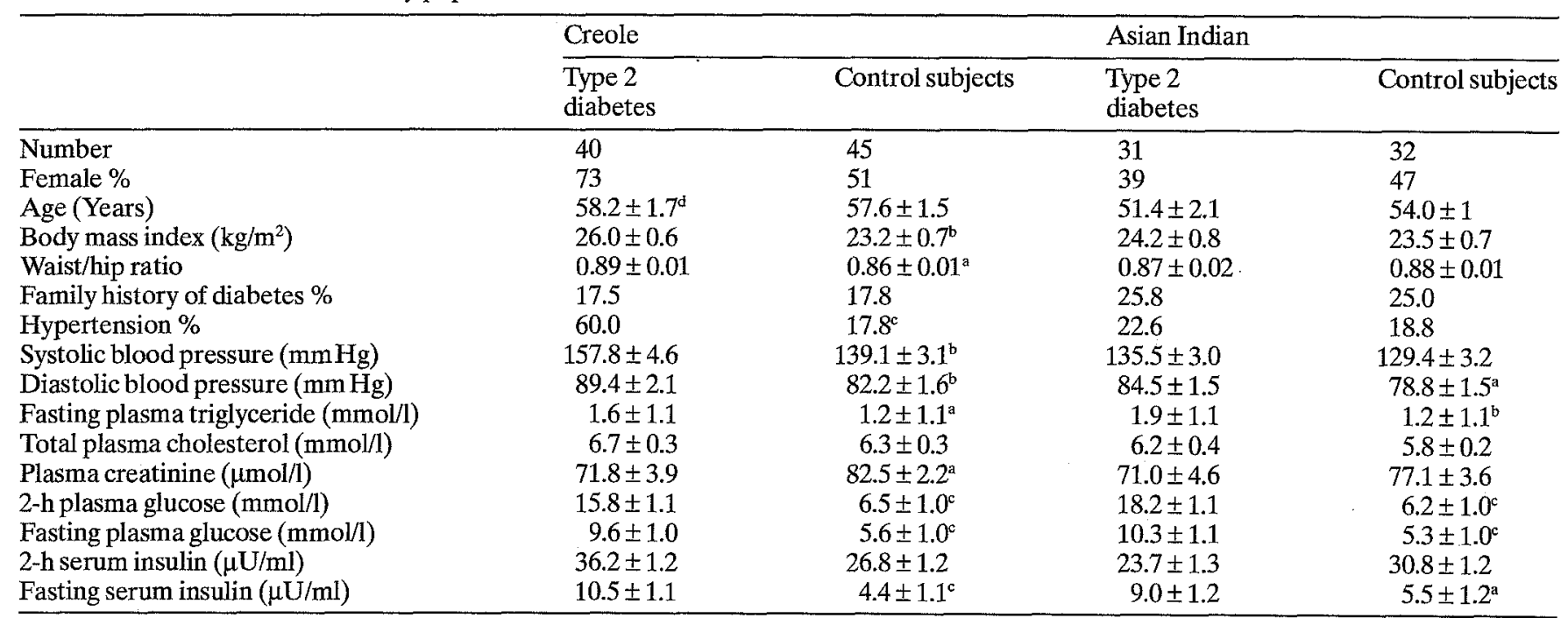

${ }^{\mathrm{a}} p<0.05,{ }^{\mathrm{b}} p<0.01,{ }^{\mathrm{c}} p<0.001$, ${ }^{\mathrm{d}}$ mean \pm standard error. Geometric means for triglycerides and fasting and 2 -h glucose and insulin

the total population $[1,2]$. The differences in body mass index and waist/hip ratio, previously shown to be independent risk factors for Type 2 diabetes in the Creoles [2] were as expected, although less obvious in the Indian sample. The differences in blood pressure and serum triglycerides were most likely secondary to Type 2 diabetes, while the differences in the plasma glucose and insulin values reflect Type 2 diabetes itself.

\section{HLA-typing}

HLA-DR allele distributions are given in Table 2, for 27 Type 2 diabetic patients and 50 healthy control subjects. There was a small increase in frequency of HLADR5 alleles in Type 2 diabetic patients when compared with control subjects, at the expense of HLA-DRw6 (DRw13, DRw14) alleles, but the differences were within the expectations of sampling fluctuations. No difference was found between the diabetic and control groups.

\section{Analysis of genotypic and allelic frequency}

After typing 85 Creoles, 4 alleles and 8 genotypes were identified (Table 3 ). The observed genotypic frequencies did not deviate from that predicted by Hardy-Weinberg equilibrium. The frequency of the $Z+2$ allele was greater in the diabetic group compared to that in the control group ( $23.8 \%$ vs $8.9 \%, p=0.008)$. The frequency of the $Z$ allele was greater in the control group compared to that in the diabetic group ( $75.6 \%$ vs $60.0 \%, p=0.03$ ), Further analysis of the Creole data according to the presence of central obesity, defined by waist/hip ratio, revealed that $\mathrm{Z}+2$ allele was associated with obese Type 2 diabetes ( $28.6 \%$ vs $5.9 \%, p=0.019$ with Yates' correction) but not lean Type 2 diabetes (Table 4). This association was not observed if the obesity was defined by BMI (data not shown). Furthermore, we also examined the clinical pa- rameters as listed in Table 1 , in the diabetic group according to the presence or absence of $Z+2$ alleles, and no difference was found between these two subgroups.

In the Indians, 3 alleles and 5 genotypes were observed from 63 individuals (Table 3 ). The $Z+10$ allele was not found in the Indians. The genotypic frequencies did not deviate from the predicted frequencies by Hardy-Weinberg equilibrium. No differences in allelic frequencies between the diabetic and control groups were observed.

\section{Analysis with logistic regression model}

In the Creoles, the $\mathrm{Z}+2$ allele appeared to be the only allele which carried a strong risk for Type 2 diabetes with a univariate odds ratio of $3.08(p=0.0416)$, as shown in Table 5 . The $Z, Z+4$, and $Z+10$ alleles showed no effect on the risk for Type 2 diabetes, in accordance with our original assumption. Among the various risk factors $(Z+2$, sex, BMI, and waist/hip ratio $), Z+2$ carried the

Table 2. HLA-DR allele distributions in Creole Type 2 diabetic patients and control subjects

\begin{tabular}{lrrrr}
\hline $\begin{array}{l}\text { HLA-DR } \\
\text { allele }\end{array}$ & \multicolumn{2}{c}{$\begin{array}{l}\text { Type 2 diabetes } \\
(n=37)\end{array}$} & & \multicolumn{2}{c}{$\begin{array}{c}\text { Control subjects } \\
n\end{array}$} & $n$ & $\%=50)$ & \\
\cline { 2 - 3 } \cline { 5 - 6 } & $n$ & & $n$ & $\%$ \\
\hline DR1 & 6 & 8.1 & 14 & 14.0 \\
DR2 & 14 & 18.9 & 15 & 15.0 \\
DR3 & 6 & 8.1 & 11 & 11.0 \\
DR4 & 6 & 8.1 & 7 & 7.0 \\
DR5 & 13 & 17.6 & 10 & 10.0 \\
DRw13 & 2 & 2.7 & 7 & 7.0 \\
DRw14 & 3 & 4.1 & 8 & 8.0 \\
DR7 & 10 & 13.5 & 8 & 8.0 \\
DRw8 & 5 & 6.8 & 9 & 9.0 \\
DR9 & 2 & 2.7 & 2 & 2.0 \\
DRw10 & 2 & 2.7 & 2 & 2.0 \\
Unassigned & 5 & 6.8 & 7 & 7.0 \\
\hline
\end{tabular}

$\mathrm{X}^{2}=8.2207$, degree of freedom $=11, p=0.693$ 
Table 3. Genotypic frequency

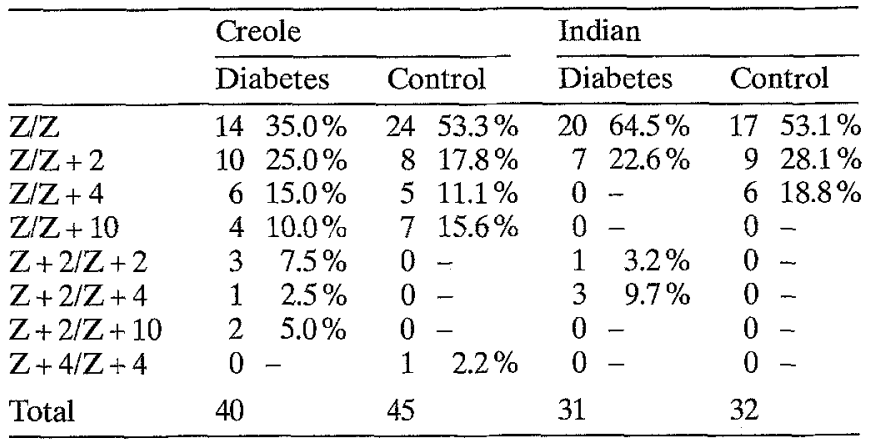

\begin{tabular}{|c|c|c|c|c|c|c|c|c|}
\hline \multicolumn{9}{|c|}{ Allelic frequency } \\
\hline & \multicolumn{4}{|c|}{ Creole } & \multicolumn{4}{|c|}{ Indian } \\
\hline & \multicolumn{2}{|c|}{ Diabetes } & \multicolumn{2}{|c|}{ Control } & \multicolumn{2}{|c|}{ Diabetes } & \multicolumn{2}{|c|}{ Control } \\
\hline$\overline{\mathrm{Z}}$ & 48 & $60.0 \%$ & 68 & $75.6 \%$ & 47 & $75.8 \%$ & 49 & $76.6 \%$ \\
\hline$Z+2$ & 19 & $23.8 \%^{\mathrm{b}}$ & 8 & $8.9 \%$ & 12 & $19.4 \%$ & 9 & $14.1 \%$ \\
\hline$Z+4$ & 7 & $8.8 \%$ & 7 & $7.8 \%$ & 3 & $4.8 \%$ & 6 & $9.4 \%$ \\
\hline$Z+10$ & 6 & $7.5 \%$ & 7 & $7.8 \%$ & 0 & - & 0 & - \\
\hline Total & 80 & & 90 & & 62 & & 64 & \\
\hline
\end{tabular}

In the Creole, when compared between diabetic and control groups: ${ }^{a} \mathrm{Z}$ vs non- $\mathrm{Z}, \mathrm{X}^{2}=4.7283$, degree of freedom $=1, p=0.03$;

${ }^{\mathrm{b}} \mathrm{Z}+2$ vs non $-\mathrm{Z}+2, \mathrm{X}^{2}=7.0014$, degree of freedom $=1, p=0.008$

Table 4. Allelic frequencies according to diabetes status and waist/hip ratio in the Creoles

\begin{tabular}{|c|c|c|c|c|c|c|c|c|}
\hline \multirow[b]{3}{*}{$\mathrm{Z}$} & \multicolumn{4}{|c|}{ Obese $^{a}$} & \multicolumn{4}{|c|}{ Lean } \\
\hline & \multicolumn{2}{|c|}{$\begin{array}{l}\text { Type } 2 \\
\text { diabetes }\end{array}$} & \multicolumn{2}{|c|}{$\begin{array}{l}\text { Control } \\
\text { subjects }\end{array}$} & \multicolumn{2}{|c|}{$\begin{array}{l}\text { Type } 2 \\
\text { diabetes }\end{array}$} & \multicolumn{2}{|c|}{$\begin{array}{l}\text { Control } \\
\text { subjects }\end{array}$} \\
\hline & 30 & $57.7 \%$ & 26 & $76.5 \%$ & 18 & $64.3 \%$ & 42 & $75.0 \%$ \\
\hline$Z+2$ & 15 & $28.6 \%^{b}$ & 2 & $5.9 \%$ & 4 & $14.3 \%$ & 6 & $10.7 \%$ \\
\hline$Z+4$ & 4 & $7.7 \%$ & 4 & $11.8 \%$ & 3 & $10.7 \%$ & 3 & $5.4 \%$ \\
\hline$Z+10$ & 3 & $5.8 \%$ & 2 & $5.9 \%$ & 3 & $10.7 \%$ & 5 & $8.9 \%$ \\
\hline Total & 52 & & 34 & & 28 & & 56 & \\
\hline
\end{tabular}

${ }^{a}$ Obese was defined by waist/hip ratio; for women $>0.838$, for men $>0.913$;

${ }^{b}$ When compared between diabetic and control group: $Z+2$ vs non-

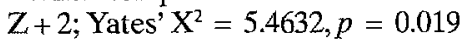

highest odds ratio $(3.08, p=0.0416)$ for Type 2 diabetes in both univariate and multivariate analysis (Table 5). However, in the multivariate odds ratio of 2.88 for the $Z+2$ allele as an independent risk factor had marginal significance $(p=0.0551)$. In the case of $Z, Z+4$, and $Z+10$, multivariate analysis has little effect on their odds ratios (data not show).

For the Indians, neither glucokinase alleles nor other factors were significant risk factors for Type 2 diabetes in this study sample (Table 5). The sample size was too small for further analysis with respect to obesity.

\section{Discussion}

The results of the present study showed that the $\mathrm{Z}+2$ allele is associated with Type 2 diabetes in Mauritian Creoles. This risk factor needs to be examined relative to other previously defined risk factors. Family history of Type 2 diabetes, earlier noted to be an independent risk factor for the disease in Mauritians [2], was excluded from the multivariate analysis since we were looking for a genetic marker. For the group as a whole however, the frequencies of glucokinase alleles did not differ between those with and those without a positive family history of diabetes in the present study.

Caution must be exercised when drawing conclusions about disease-susceptibility genes in mixed populations, especially when the degree of genetic admixture might be different in the disease and control groups. For example, differences in the degree of genetic admixture were readily apparent between South Pacific Type 2 diabetic patients and control subjects when the frequencies of HLA alleles were compared in these groups [23]. In the current study, however, the Mauritian Creole subjects were typed at the HLA locus, and the frequencies of HLA alleles were found to not differ between Type 2 diabetic patients and control subjects. Based on this data, it is less likely that differences in genetic admixture between the two groups can account for the differences in glucokinase allele frequencies observed.

Obesity is a well-known risk factor for Type 2 diabetes, and previous studies have shown that both body mass index and waist/hip ratio were independent predictors of the disease in Mauritians [2]. Further, the diabetic and control groups differed by both BMI and waist/hip ratio. Accordingly, we extended the analysis to determine the frequency of glucokinase alleles with respect to obesity in Type 2 diabetes and control subjects. In the lean subgroup, either defined by BMI $\left(\leq 25.768 \mathrm{~kg} / \mathrm{m}^{2}\right.$ for women, $\leq 24.267$ $\mathrm{kg} / \mathrm{m}^{2}$ for men) or waist/hip ratio ( $\leq 0.838$ for women, $\leq 0.913$ for men), no difference in allelic frequency was noted between the Type 2 diabetic and the control subjects. In the obese subgroup however, defined by waist/hip ratio (but not by BMI), the $\mathrm{Z}+2$ allele was positively associated with Type 2 diabetes $(28.8 \%$ vs $5.9 \%, p=0.019$, after Yates' correction). High waist/hip ratio has been reported to be a better predictor for Type 2 diabetes than BMI, particularly in women [2]. However, $\mathrm{Z}+2$ allele was not associated with high waist/hip ratio. These results suggest that a glucokinase allele in linkage disequilibrium with the $\mathrm{Z}+2$ marker, may be associated with an obese phenotype in Type 2 diabetic patients. This observation must be confirmed in a larger population, however, as the current analysis of subgroups considerably reduced the sample sizes. The relationship between obesity, Type 2 diabetes, and glucokinase alleles should also be evaluated in other populations. It is interesting to speculate that a defective hepatic glucokinase might favour peripheral glucose disposal in skeletal muscle and adipose tissue.

It is not surprising that a positive association of a glucokinase allele with Type 2 diabetes was found in the Creoles, but not in the Indians, since different genetic factors are likely to play a role in various ethnic groups [24]. As part of the genetic admixture in Creoles was contributed by Mauritian Indians, lack of association between this genetic marker and Type 2 diabetes in the Indians suggests that Creoles did not acquire this genetic trait from Indians. Thus, the source for this genetic marker would more likely be the African Blacks or European Caucasian background. 
Table 5. Risk of Type 2 diabetes by glucokinase genotype and other risk factors in the Mauritian population

\begin{tabular}{|c|c|c|c|c|}
\hline \multicolumn{5}{|l|}{ Creole } \\
\hline \multirow[b]{2}{*}{ Risk factor } & \multicolumn{2}{|c|}{ Univariate } & \multicolumn{2}{|c|}{ Multivariate } \\
\hline & $\begin{array}{l}\text { Odds } \\
\text { ratio }\end{array}$ & $95 \%$ C.I. & $\begin{array}{l}\text { Odds } \\
\text { ratio }\end{array}$ & $95 \%$ C.I. \\
\hline At least one $\mathrm{Z}+2$ Allele & 3.08 & $1.14-8.35^{\mathrm{a}}$ & 2.88 & $0.98-8.50$ \\
\hline $\begin{array}{l}\text { Female } \\
\text { Age (years) } \\
\text { Body mass index }\left(\mathrm{kg} / \mathrm{m}^{2}\right) \\
\text { Waist/hip ratio }(1 / 10)\end{array}$ & $\begin{array}{l}2.58 \\
1.01 \\
1.19 \\
2.50\end{array}$ & $\begin{array}{l}1.08-6.19^{\mathrm{a}} \\
0.97-1.04 \\
1.06-1.33^{\mathrm{a}} \\
1.24-5.03^{\mathrm{a}}\end{array}$ & $\begin{array}{l}2.86 \\
1.01 \\
1.07 \\
2.43\end{array}$ & $\begin{array}{l}0.85-9.58 \\
0.96-1.06 \\
0.92-1.23 \\
1.02-5.79^{a}\end{array}$ \\
\hline $\begin{array}{l}\text { At least one } Z \text { Allele } \\
\text { At least one } Z+4 \text { Allele } \\
\text { At least one } Z+10 \text { Allele }\end{array}$ & $\begin{array}{l}0.13 \\
1.38 \\
0.96\end{array}$ & $\begin{array}{l}0.015-1.12 \\
0.42-4.51 \\
0.29-3.13\end{array}$ & & \\
\hline \multicolumn{5}{|l|}{$\overline{\text { Indian }}$} \\
\hline & \multicolumn{2}{|c|}{ Univariate } & \multicolumn{2}{|c|}{ Multivariate } \\
\hline Risk factor & $\begin{array}{l}\text { Odds } \\
\text { ratio }\end{array}$ & $95 \%$ C.I. & $\begin{array}{l}\text { Odds } \\
\text { ratio }\end{array}$ & $95 \%$ C.I. \\
\hline At least one $\mathrm{Z}+2$ Allele & 1.41 & $0.48-4.08$ & 1.17 & $0.37-3.73$ \\
\hline $\begin{array}{l}\text { Female } \\
\text { Age (years) } \\
\text { Body mass index }\left(\mathrm{kg} / \mathrm{m}^{2}\right) \\
\text { Waist/hip ratio }(1 / 10)\end{array}$ & $\begin{array}{l}0.72 \\
0.98 \\
1.04 \\
0.89\end{array}$ & $\begin{array}{l}0.26-1.95 \\
0.93-1.02 \\
0.92-1.18 \\
0.48-1.65\end{array}$ & $\begin{array}{l}0.37 \\
0.99 \\
1.10 \\
0.52\end{array}$ & $\begin{array}{l}0.07-2.12 \\
0.94-1.05 \\
0.95-1.27 \\
0.17-1.59\end{array}$ \\
\hline $\begin{array}{l}\text { At least one } Z \text { Allele } \\
\text { At least one } Z+4 \text { Allele }\end{array}$ & $\begin{array}{l}\mathrm{N} / \mathrm{A} \\
0.46\end{array}$ & $\begin{array}{l}\text { N/A } \\
0.11-2.05\end{array}$ & & \\
\hline
\end{tabular}

${ }^{a} p<0.05$; C.I., confidence interval; N/A, Not available, since all subjects have at least one $\mathrm{Z}$ allele

We have evaluated the frequency of glucokinase alleles in a population of American Black Type 2 diabetic patients and control subjects (unpublished data). America Blacks, like Mauritian Creoles, brought from Africa between 1710-1810, also share genetic admixture with European Caucasians. Interestingly, the most common allele (Z) was noted to have a negative association with Type 2 diabetes in both American Blacks and Mauritian Creoles. This finding suggests that perhaps the $Z$ allele represents the "wild type" allele (normal, not defective) of the glucokinase gene. Further, the $Z$ allele has highest frequency in these two populations regardless the diabetic phenotype. In the American Black study the $Z+4$ allele, in contrast to the $\mathrm{Z}+2$ allele in Mauritius Creoles, was found to be associated with Type 2 diabetes. For American Blacks $Z+4$ was an independent risk factor with odds ratio of 2.85 ( $p=$ 0.0018 ), after adjusting for age, sex, and BMI. These two ethnic groups differ in that American Blacks originated from West Africa, predominantly Nigeria, while the Creoles were originally from Madagascar and the French African colonies. The different alleles associated with Type 2 diabetes in the two ethnic groups suggest that two different biological variants of glucokinase may be operating. This hypothesis can be tested, once the sequence of the structural portions and regulatory regions of the normal glucokinase gene have been defined in these two ethnic groups.

In addition to the environmental factors reported previously $[1,2]$, the results of the current study lend further support to the prospect that genetic factors also play a role in the pathogenesis of Type 2 diabetes. As shown by the genotypic frequencies, one can calculate that $40 \%$ of Mauritius Creole Type 2 diabetic patients had at least one $\mathrm{Z}+2$ allele, compared to $17.8 \%$ of control subjects $\left(\mathrm{X}^{2}=\right.$ 5.1609 , degree of freedom $=1, p=0.023$ ). In conclusion, the glucokinase gene might be involved in the pathogenesis of Type 2 diabetes in Mauritian Creoles, but not in Indians. This remains to be determined, as glucokinase activity has not been shown to be defective in islet-Beta cells or liver of Type 2 diabetic patients. The results of the current study, however, suggest that this locus could serve as a marker for a subtype of Type 2 diabetes which would have profound implications for the epidemiology and prevention/treatment of this disease.

Acknowledgements. This study was supported in part by grants DK07120 (KCC), DK16746 (MA Permutt), GM 28719 (MA Province), and DK25446 (PZZ, GKD) from the National Institutes of Health. We are grateful to the Ministry of Health Mauritius and the other members of the Mauritius Noncommunicable Disease Study Group for their roles in the data collection. The laboratory assistance of Ms. C. Welling, Ms. R. Janssen, and manuscript preparation by Ms. J. Wokurka are also gratefully acknowledged.

\section{References}

1. Dowse GK, Gareeboo H, Zimmet PZ, et al. (1990) High prevalence of NIDDM and impaired glucose tolerance in Indian, Creole, and Chinese Mauritians. Diabetes 39: 390-396

2. Dowse GK, Gareeboo H, Zimmet PZ, et al. (1990) Abdominal obesity and physical inactivity as risk factors for NIDDM and impaired glucose tolerance in Indian, Creole, and Chinese Mauritians. Diab Dare 14:271-282

3. McLarty DG, Pollitt C, Swai ABM (1990) Diabetes in Africa. Diabetic Med 7:670-684

4. Ahuja MMS (1979) Epidemiological studies on diabetes mellitus in India. In: Ahuja MMS (ed) Epidemiology of diabetes in developing countries. Interprint, New Delhi, pp 29-38

5. Harris MI (1990) Noninsulin-dependent diabetes mellitus in Black and White Americans. Diab Metab Rev 6: 71-90

6. Omar MAK, Seedat MA, Dyer RB, Rajput MC, Motala AA (1985) The prevalence of diabetes mellitus in a large group of South African Indians. S Afr Med J 67: 924-926

7. Ramachandran A, Mohan V, Snehalatha C, Viswanathan M (1988) Prevalence of non-insulin-dependent diabetes mellitus in Asian Indian families with a single diabetic parent. Diabetes Res Clin Prac 4: 241-245

8. Zimmet P, Dowse G, Finch C(1990) The epidemiology and natural history of NIDDM - lessons from the South Pacific. Diab Metab Rev 6: 91-124

9. Knowler WC, Pettitt DJ, Saad MF, Bennett PH (1990) Diabetes mellitus in the Pima Indians: incidence, risk factors and pathogenesis. Diab Metab Rev 6: 1-27

10. Rotter J, Vadheim CM, Rimoin DL (1990) Genetics of diabetes mellitus. In: Rifkin H, Porte DJr (eds) Diabetes mellitus. Elsevier, New York, pp 378-413

11. Cox NJ, Bell GI (1989) Disease associations. Diabetes 38: 947-50

12. Magnuson MA (1990) Glucokinase gene structure. Diabetes 39: $523-527$

13. Matschinsky FM (1990) Glucokinase as glucose sensor and metabolic signal generator in pancreatic $\beta$-cells and hepatocytes. Diabetes 39: 647-652

14. Tanizawa Y, Koranyi LI, Welling CM, Permutt MA (1991) Human liver glucokinase gene: cloning and sequence determination of two alternatively spliced cDNAs. Proc Natl Acad Sci USA 88: 7294-7297

15. Matsutani A, Janssen R, Donis-Keller H, Permutt MA (1992) A polymorphic (CA) repeat element maps the human glucokinase gene to chromosome 7p. Genomics 12:319-325 
16. WHO Study Group (1985) Diabetes Mellitus. Geneva, World Health Organization. (Tech. Rep. Ser., No.727)

17. Todd JA, Bell JI, McDevitt HO (1987) HLA-DQ $\beta$ gene contributes to susceptibility and resistance to insulin-dependent diabetes mellitus. Nature 329: 599-604

18. Gao X, Serjeantson SW (1991) Heterogeneity in HLA-DR2-related DR,DQ haplotypes in eight populations of Asia-Oceania. Immunogenetics 34: 401-408

19. Grizzle JE, Starmer CF, Koch GG (1969) Analysis of categorical data by linear models. Biometrics 25: 489-504

20. Litt M, Luty JA (1989) A hypervariable microsatellite revealed by in vitro amplification of a dinucleotide repeat within the cardiac actin gene. Am J Hum Genet 44:397-401

21. Weber JL, May PE (1989) Abundant class of human polymorphisms which can be typed using the polymerase chain reaction. Am J Hum Genet 44: 388-396

22. Weber JL (1990) Informativeness of human $(\mathrm{dC}-\mathrm{dA})_{\mathrm{n}}(\mathrm{dG}-\mathrm{dT})_{\mathrm{n}}$ polymorphism. Genomics 7:524-530
23. Serjeantson SW, Owerbach D, Zimmet P, Nerup J, Thoma K (1983) Genetics of diabetes in Nauru: effects of foreign admixture. HLA antigens and the insulin-gene-linked polymorphism. Diabetologia 25: 13-17

24. Zimmet $P$ (1982) Type 2 (non-insulin-dependent) diabetes - An epidemiological overview. Diabetologia 22:399-411

Received: 15 November 1991

and in revised form: 13 February 1992

Dr. M. A.Permutt

Metabolism Division

Washington University School of Medicine

660 S. Euclid Avenue

Box 8127

St. Louis, MO 63110

USA 